\title{
Avaliação de protótipo de unidade de preparo de fluidos de perfuração automatizada
}

\author{
I. J. SILVA ${ }^{1}$, S. C. OLIVEIRA ${ }^{1}$, S. C. MAGALHÃES ${ }^{1}$, L.A. CALÇADA ${ }^{1}$ e C. M. SCHEID ${ }^{1}$ \\ ${ }^{1}$ Universidade Federal Rural do Rio de Janeiro, Departamento de Engenharia Química \\ BR 465, km 7, CEP 23890-000 \\ E-mail para contato: scheid@ufrrj.br
}

\begin{abstract}
RESUMO - Os fluidos de perfuração são fundamentais durante a perfuração de um poço de petróleo. O fluido é escolhido de acordo com suas propriedades físicoquímicas, estabelecidas pelo técnico de perfuração considerando as necessidades operacionais do poço. Desta forma, este trabalho teve como objetivo avaliar a capacidade de um sistema de preparação de fluidos de perfuração em tempo real, denominado Unidade Móvel de Preparação Automática de Fluidos (UMPAF). Esta unidade é acoplada a outra responsável pela aferição de propriedades do fluido (Unidade Móvel de Pesquisa Científica - UMPC). A integração entre elas é realizada por um software desenvolvido para este fim. O sistema é capaz de produzir fluidos de perfuração e manter suas propriedades físico-químicas dentro das especificações de forma automática e remota. Para a avaliação da UMPAF, foram realizados testes de operacionalidade, com a preparação de fluidos a base água que mostraram que além de preparar, a unidade é capaz de controlar as propriedades frente a perturbações externas, receber, tratar e organizar comandos de forma inteligível, conseguindo por si só, manter o valor desejado das propriedades dentro das especificações informadas ao software.
\end{abstract}

\section{INTRODUÇÃO}

Os fluidos de perfuração são indispensáveis no processo de perfuração de poços de petróleo. O sucesso da perfuração depende de um bom desempenho dos fluidos, que têm como funções: carrear os cascalhos gerados pela broca até a superfície, exercer pressão hidrostática sobre as formações, estabilizar as paredes do poço, resfriar e lubrificar a coluna de perfuração e a broca, entre outras (Thomas et al. 2001).

Existem duas classificações principais para os fluidos de perfuração: fluidos de base água e fluidos de base sintética. Os fluidos de base água tem como componente principal água, sólidos adensantes, viscosificantes, antiespumantes e redutores de filtrado. Os fluidos de base sintética são, em geral, formados por emulsões estáveis de n-parafinas ou ésteres de ácidos graxos de óleos vegetais com água, além de sólidos adensantes, viscosificantes, e obrigatoriamente componentes emulsificantes (Almeida et al. 2010).

Para cada etapa da perfuração, os fluidos utilizados são determinados de acordo com as necessidades operacionais do poço e suas propriedades físico-químicas, como viscosidade e densidade, que devem ser mantidas dentro de uma faixa operacional, pré-determinada pelo engenheiro responsável pela sonda (Caenn et al. 1996, Apaleke et al. 2012, Azar e Samuel, 
2007). Tecnologias para aferição em tempo real destas propriedades praticamente não existem no mercado. Entretanto, foi desenvolvido por Magalhães (2015) um sistema automatizado de aferição remota das propriedades físico-químicas de fluidos de perfuração, denominada Unidade Móvel de Pesquisa Científica (UMPC). Estas propriedades, tais como: viscosidade aparente e densidade, estabilidade elétrica, concentração de água em óleo e concentração de sólidos totais em suspensão são aferidas.

Este trabalho visou avaliar a capacidade da Unidade Móvel de Preparação Automática de Fluidos (UMPAF) de preparar e controlar automaticamente as propriedades do fluido de perfuração desejado. Os testes de operacionalidade para preparação de fluidos a base água realizados mostraram que a unidade foi capaz de produzir fluidos de perfuração e manter suas propriedades físico-químicas dentro das especificações determinadas pelo operador no software de forma automática e remota, mesmo frente a perturbações no sistema.

\section{METODOLOGIA}

A figura 1 apresenta um esquema da UMPAF. A unidade experimental consiste de um tanque mestre, o qual recebe os insumos de adensamento e viscosificação dos fluidos de perfuração, que estão dispostos em dois dosadores de sólidos, além de água. O fluido no interior do tanque mestre é bombeado continuamente para a UMPC projetada e desenvolvida por Magalhães (2015), onde sensores aferem as propriedades físico-químicas do mesmo. $\mathrm{O}$ sistema é um loop fechado de escoamento, onde o fluido vai aos sensores e retorna ao tanque, sendo seu gerenciamento totalmente automatizado por um sistema supervisório.

Figura 1 - Ilustração da unidade experimental.

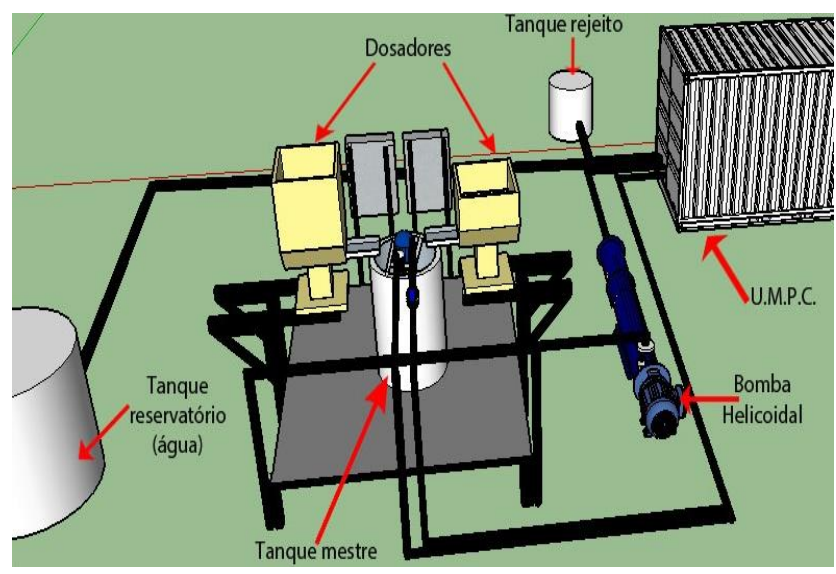

Para operar a UMPAF e integrá-la a UMPC é utilizado um software que foi desenvolvido no Laboratório de Escoamento de Fluidos (LEF), na Universidade Federal Rural do Rio de Janeiro. Para sua confecção, as lógicas fuzzy e booleana foram utilizadas. A lógica booleana é baseada em resultados binários, ou seja, 0 ou 1 , sim ou não, verdadeiro ou falso. A lógica fuzzy é uma extrapolação da lógica booleana, que admite valores lógicos entre o verdadeiro e falso, um "talvez". Foram desenvolvidas regras que controlam as variáveis do sistema como o nível do tanque, o bombeio do fluido no interior do tanque, a agitação no tanque central, a identificação do fluido, o controle de densidade e viscosidade e acerca das flexibilizações de set point e flexibilização de operação. 
A figura 2 apresenta a interface homem-máquina (IHM) gerada pelo software. Por ela é possível acessar e obter os dados do ambiente virtual e, dessa forma, operar a unidade mestre preparando um fluido de perfuração ou corrigindo as propriedades de um já existente.

Figura 2 - Foto da IHM construída para a UMPAF.

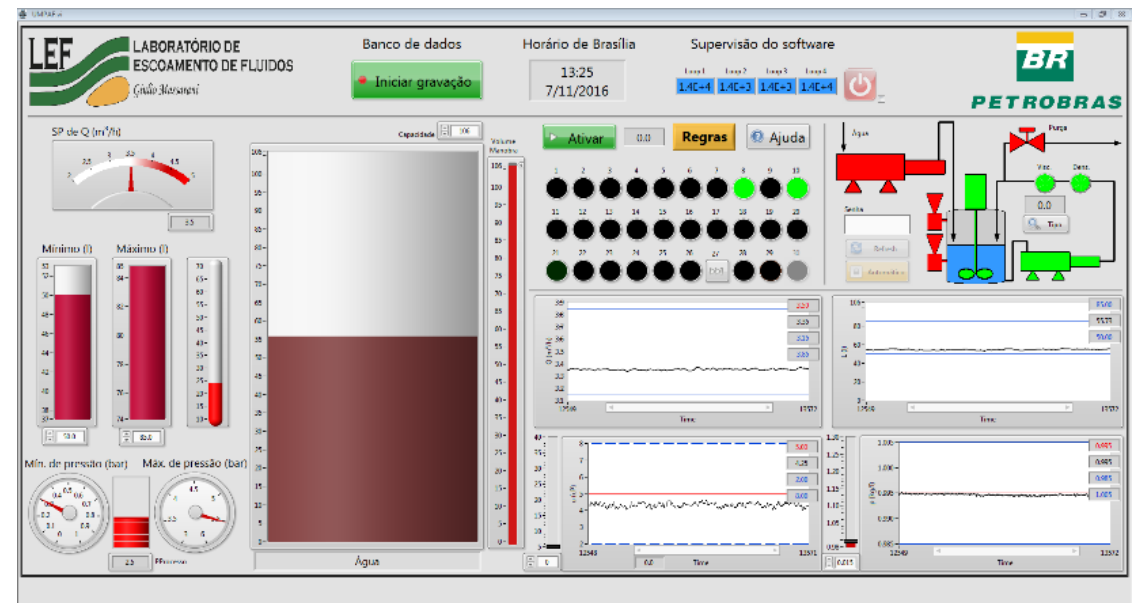

\section{RESULTADOS E DISCUSSÃO}

Com intuito de avaliar a capacidade da UMPAF de preparar e controlar automaticamente as propriedades do fluido de perfuração estipuladas através de um set point, foram realizados testes de operacionalidade. O teste servo foi usado para verificar a atuação do controlador diante o set point, ao estipular uma vazão mais alta que a anterior, por exemplo. O teste regulatório foi feito para observar a ação do sistema diante de uma perturbação, seja ela um vazamento na linha ou um transbordamento no tanque, mantendo assim o set point definido.

Figura 3 - Resultados do teste servo e regulatório observada em função do tempo (a) de vazão volumétrica (b) do volume do tanque.
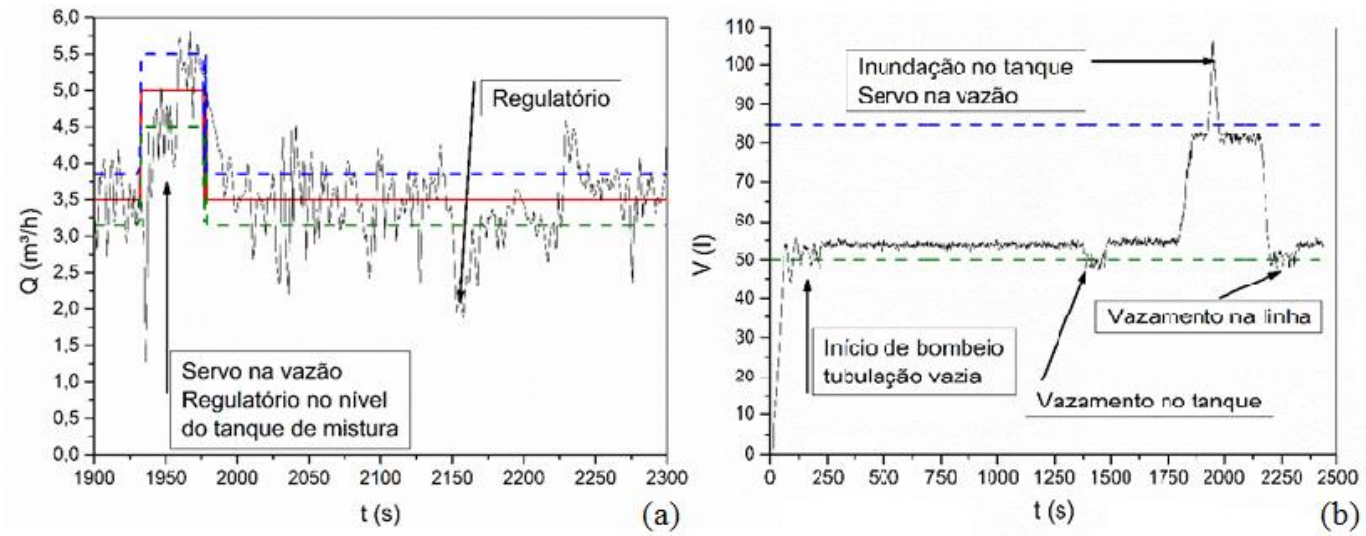

Inicialmente, foi definido um set point automático de operacionalidade de vazão volumétrica à $3,5 \mathrm{~m}^{3} / \mathrm{h}$. Em seguida, realizou-se um teste servo, aumentando-se a vazão de 3,5 
$\mathrm{m}^{3} / \mathrm{h}$ para $5,0 \mathrm{~m}^{3} / \mathrm{h}$ e novamente voltando para $3,5 \mathrm{~m}^{3} / \mathrm{h}$. É possível observar na Figura 4 abaixo que o sistema pôde, satisfatoriamente, controlar e manter o set point.

Logo em seguida foram realizados testes regulatórios, simulando um aumento no nível do tanque, vazamento no tanque e vazamento na linha, respectivamente. Como pode ser observado na Figura 3 (b) em termos de volume em função do tempo.

Após o primeiro experimento com água pura, iniciou-se os testes com os dosadores de sólidos, utilizando adensantes e viscosificantes, para preparo dos fluidos de perfuração. Inicialmente, um fluido de base polimérica foi preparado. Utilizou-se Goma Xantana/CMC como viscosificante e Barita como adensante. O set point foi definido para o preparo de um fluido com viscosidade de $35 \mathrm{cP}$ e densidade $1,14 \mathrm{~kg} / \mathrm{l}$.

Nos gráficos abaixo foi utilizado como eixo das coordenadas as propriedades de viscosidade (parte superior) e densidade (parte inferior), das quais estão sendo aferidas concomitantemente. Na Figura 4(a), no tempo aproximado de 1850s foi feito primeiramente o aumento da viscosidade, podendo ser observado que ao adicionar viscosificante a densidade do fluido não foi afetada significativamente. Após o tempo aproximado de 4600s, observa-se que a dosagem de adensante também não afetou na viscosidade quando foi requerido o aumento na densidade do fluido. Após o tempo de 5550s, o sistema foi capaz de manter o fluido de perfuração dentro da faixa de set point estabelecido.

Figura 4 - Resultados do controle de viscosidade e densidade em função do tempo para fluido de perfuração com base polimérica; (a) definido o set point de viscosidade e densidade (b) teste regulatório adicionando-se barita.
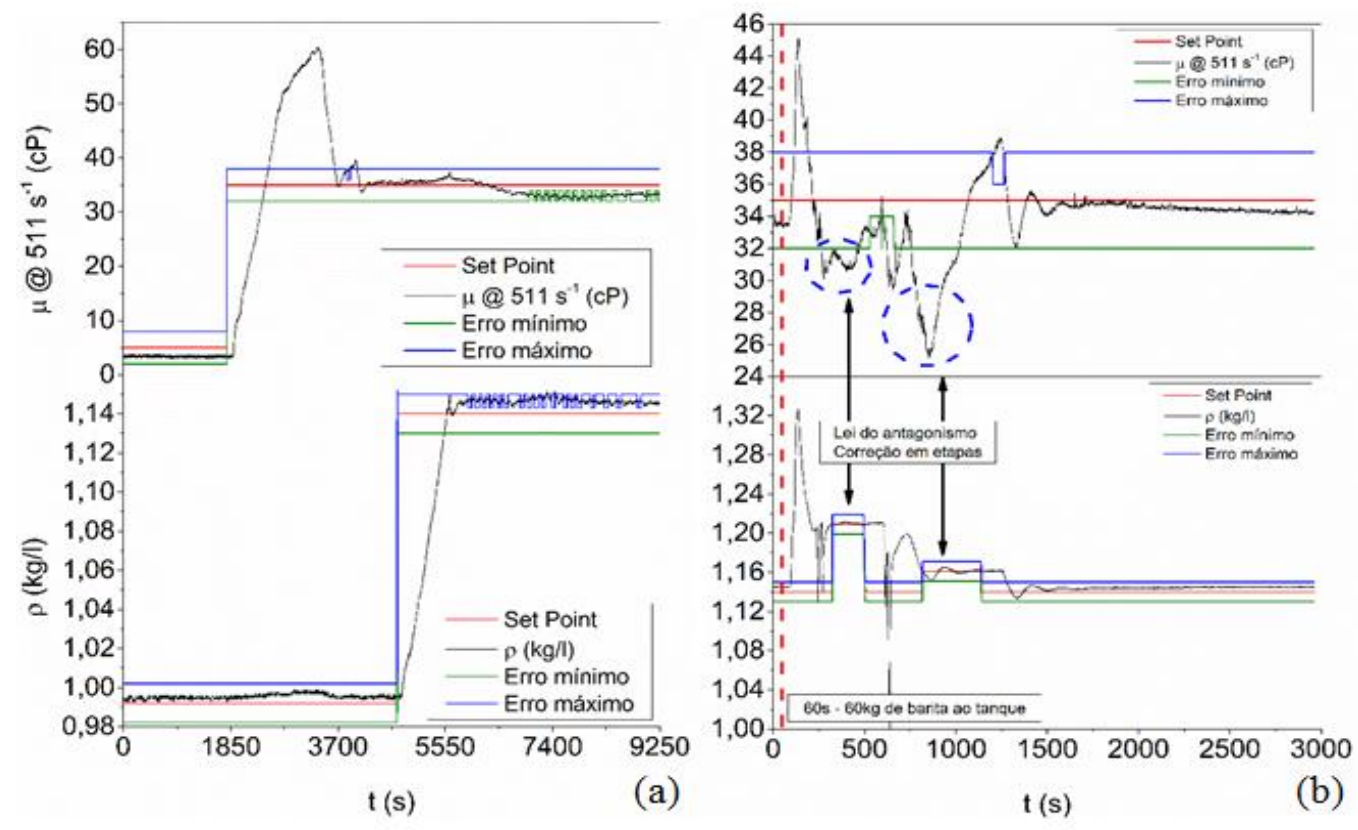

Para o mesmo fluido, foi realizado uma perturbação no sistema para teste regulatório, com a adição de quantidade de barita superior à necessária para aumentar a densidade determinada no set point, o que pode ser observada na Figura 4(b). No tempo próximo a 0s foi 
feita a perturbação do sistema adicionando-se barita no tanque, sendo possível observar o aumento no valor de viscosidade e densidade. Para contornar esta situação, o sistema imediatamente atuou adicionando água, sendo observado na diminuição dos valores das propriedades. Após o tempo aproximado de 1500s o sistema perturbado voltou ao valor inicial de set point definido.

Como é possível observar na Figura 4(a), houve um overshoot na viscosidade do fluido, no qual aumentou infinitamente até a regra de adição de água ser acionada para controlar e voltar ao set point. Este tipo de overshoot causa perda de material, gasto energético, aumento do material purgado, o que são contratempos indesejáveis. Novas regras foram criadas para o funcionamento do software: uma para que haja um aumento gradativo da viscosidade, ou seja, haverá um doseamento de viscosificante durante determinado tempo e logo após haverá um tempo de pausa para ocorrer a homogeneização do fluido, e outra para quando o fluido possuir base argilosa, onde ocorrerá o doseamento constante de viscosificante até a detecção cinética de viscosificação. O novo resultado para base polimérica pode ser conferido na Figura 5, do qual é perceptível o melhoramento do método antigo.

Figura 5 - Resultados de viscosidade em função do tempo para fluido de perfuração com base polimérica com nova metodologia.

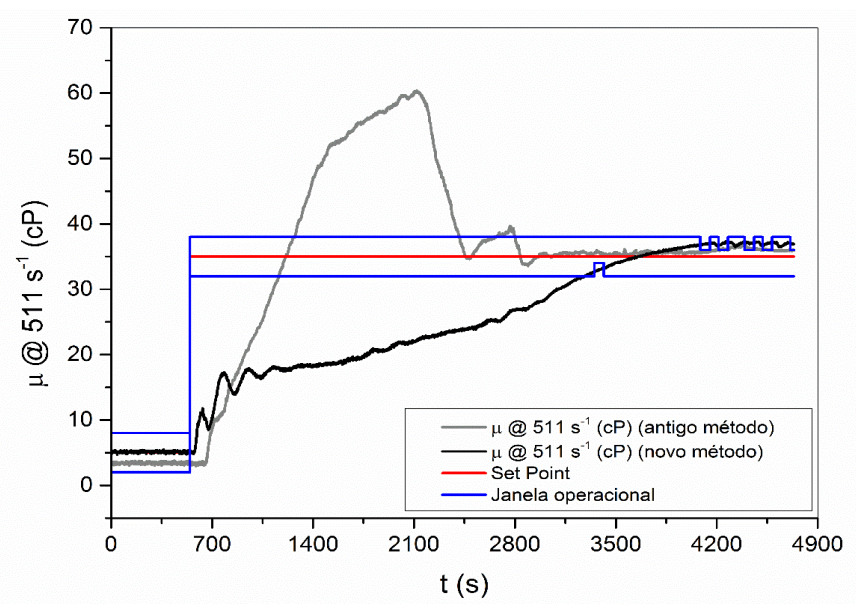

\section{CONCLUSÃO}

Através da avaliação da Unidade Móvel de Preparação Automática de Fluidos (UMPAF), foi possível comprovar que o sistema foi capaz de receber, tratar e organizar comandos de forma inteligível, conseguindo por si só, sem a intervenção humana, manter o set point de densidade, viscosidade, vazão volumétrica e volume dentro das especificações escolhidas pelo operador e definidas no software, mesmo com a presença de perturbações. É possível concluir também que mesmo com modificações nas caixas de controle dos dosadores de sólidos, os mesmos foram capazes de atender rigorosamente as demandas de preparação automática de fluido. 


\section{REFERÊNCIAS}

ALMEIDA, R. D. F.; SILVA, W. G. A. L., 2010. Avaliação de fluidos de perfuração de base aquosa contendo poliglicóis modificados. Projeto final de Curso - Escola Politécnica da Universidade Federal do Rio de Janeiro, Rio de Janeiro.

APALEKE A. S, AL-MAJED A., HOSSAIN M. E., 2012. Drilling fluid: state of the art and future trend. North Africa technical conference and exhibition, Cairo, Egypt.

AZAR J. J., SAMUEL G. B., 2007. Drilling Engineering. PennWell Corporation.

CAENN, R., CHILlingAR G.V., 1996. Drilling fluids: State of the Art. Journal of Petroleum Science and Engineering. Issue 14, pages 221-230.

THOMAS, J. E., 2001. Fundamentos de Engenharia de Petróleo. Editora Interciência, $2^{\circ}$ Edição, Rio de Janeiro.

GOMIDE, F. A. C, GUDWIN, R. R, TANSCHEIT, R., 1995. Conceitos fundamentais da teoria de conjuntos fuzzy, lógica fuzzy e aplicações. Universidade Estadual de Campinas - UNICAMP, São Paulo.

MAGALHÃES, S., 2015. UMPC - Unidade Móvel de Pesquisa Científica: um sistema desenvolvido para aferições em tempo real das propriedades físico-químicas de fluidos de perfuração. 333 f. Dissertação (Mestrado) - Curso de Engenharia Química, Universidade Federal Rural do Rio de Janeiro, Seropédica, 2015. 